\title{
Effective viscosity and Reynolds number of non- Newtonian fluids using Meter model
}

DOI:

https://doi.org/10.1007/s00397-020-01248-y

\section{Document Version}

Accepted author manuscript

Link to publication record in Manchester Research Explorer

\section{Citation for published version (APA):}

Shende, T., Niasar, V., \& Babaei, M. (2021). Effective viscosity and Reynolds number of non-Newtonian fluids using Meter model. Rheologica Acta, 60(1), 11-21. https://doi.org/10.1007/s00397-020-01248-y

\section{Published in:}

Rheologica Acta

\section{Citing this paper}

Please note that where the full-text provided on Manchester Research Explorer is the Author Accepted Manuscript or Proof version this may differ from the final Published version. If citing, it is advised that you check and use the publisher's definitive version.

\section{General rights}

Copyright and moral rights for the publications made accessible in the Research Explorer are retained by the authors and/or other copyright owners and it is a condition of accessing publications that users recognise and abide by the legal requirements associated with these rights.

\section{Takedown policy}

If you believe that this document breaches copyright please refer to the University of Manchester's Takedown Procedures [http://man.ac.uk/04Y6Bo] or contact uml.scholarlycommunications@manchester.ac.uk providing relevant details, so we can investigate your claim.

\section{OPEN ACCESS}




\title{
Effective viscosity and Reynolds number of non-Newtonian fluids using Meter model
}

\author{
Takshak Shende • Vahid J Niasar . \\ Masoud Babaei
}

Received: 22 May 2020 / Revised: 7 Sept 2020 / Accepted: 28 Sept 2020

\begin{abstract}
The Meter model (a four-parameter model) captures shear viscosityshear stress relationship (S-shaped type) of polymeric non-Newtonian fluids. We devise an analytical solution for radial velocity profile, average velocity and volumetric flow rate of steady state laminar flow of non-Newtonian Meter model fluids through a circular geometry. The analytical solution converts to the HagenPosseuille equation for the Newtonian fluid case. We also develop the formulations to determine effective viscosity, Reynolds number and Darcy's friction factor using measurable parameters as available rheological models do not correctly define these parameters for a given set of flow condition in circular geometry. The analytical solution and formulations are validated against experimental data. The results suggest that the effective Reynolds number and effective friction factor estimated using the proposed formulation helps to characterise non-Newtonian fluid flow through a circular geometry in laminar and turbulent flow.
\end{abstract}

Keywords Non-Newtonian fluid · Shear stress · Viscosity · Analytical solution · Shear-thinning fluid · Reynolds number · Micro-capillary fluid flow

\section{Introduction}

The laminar flow of a non-Newtonian fluid (described using generalised Newtonian fluid model) through a circular capillary/tube has broader engineering application (e.g. polymer fluid flow through pipes in an industrial settings (Bird et al, 1987), capillary bundle model of a porous media (Savins, 1969), pore-Network model (Sochi and Blunt, 2008)). Amongst generalised Newtonian fluid models (Yilmaz and Gundogdu, 2008), Cross (Cross, 1965), Carreau (Yasuda, 1979), CarreauYasuda (Yasuda, 1979), Meter (Meter and Bird, 1964; Meter, 1964; Savins, 1969 , Tsakiroglou, 2002, Tsakiroglou et al, 2003b a), and Steller-Ivako model (Steller and Iwko, 2018) can predict S-shaped rheological properties (i.e. constant viscosity at

Corresponding Author: Masoud Babaei

The University of Manchester, Department of Chemical Engineering and Analytical Science, Manchester, UK

E-mail: masoud.babaei@manchester.ac.uk 
low and high shear values and decreasing viscosity at intermediate shear values) of many shear-thinning fluids.

Attempts have been made by many investigators to obtain analytical solution for flow of non-Newtonian fluid through a circular tube. Matsuhisa and Bird derived an analytical solution for the laminar flow of a fluid obeying shear stressdependent Ellis model (Matsuhisa and Bird, 1965). Meter and Bird proposed the analytical solution for the flow of shear stress-dependent Meter model fluid in a circular capillary if $\frac{\eta_{\infty}}{\eta_{0}}$ is very small. Here, $\eta_{0}$ and $\eta_{\infty}$ are zero and infinite shear viscosity respectively (Meter and Bird, 1964). Although Sochi (Sochi, 2015) and Kim (Kim, 2018) proposed analytical solutions for Carreau and Cross fluid flow through a circular tube and Peralta et al., (Peralta et al, 2014, 2017) proposed analytical solution for flow over free-draining vertical plate, the exact analytical solution is absent for estimation of the radial velocity profile, average velocity and volumetric flow rate of fluid flow in a circular tube/micro-capillary obeying Cross, Carreau, Meter, or Steller-Ivako model.

The Reynolds number of non-Newtonian fluids in a circular tube/capillary is commonly defined using the viscosity of the fluid at the wall (Escudier et al, 2005 . Kim, 2018), the zero-shear viscosity (Ferrás et al, 2020) or Metzner and Reeds equation (Metzner and Reed, 1955). The shear viscosity of non-Newtonian fluids vary along the radial direction in a fully developed circular capillary. Thus, zero shear viscosity or the viscosity of the fluid at the wall is not the representative viscosity or the effective viscosity of fluid flow. Metzner and Reeds equation is applicable for purely power-law fluid.

The effective viscosity of the fluid is analogous to the average velocity of the fluid. Both vary spatially during fluid flow in the circular capillary. Thus, similar to the average velocity value, the effective viscosity value is a single representative viscosity value for fluid flow under a given set of conditions. Sadowski and Bird (Sadowski and Bird, 1965) defined the effective viscosity of the Ellis model fluid, as in Eq. 1 1 based on the exact analytical solution for the flow of the Ellis model fluid in the circular capillary:

$$
\frac{1}{\eta_{\mathrm{eff}}}=\frac{1}{\eta_{0}}\left(1+\frac{4}{\alpha+3}\left(\frac{\tau_{\mathrm{w}}}{\tau_{\frac{1}{2}}}\right)^{\alpha-1}\right)
$$

here, $\eta_{\text {eff }}$ is the effective viscosity of the fluid, $\eta_{0}$ is the zero shear viscosity, $\alpha$ is an exponent, $\tau_{\frac{1}{2}}$ is the critical shear stress parameter, and $\tau_{\mathrm{w}}$ is the wall shear stress. The effective viscosity helps to define the Reynolds number and Darcy's friction factor. Further, effective viscosity helps to upscale shear viscosity from pore-scale to Darcy scale (Savins, 1969, Sadowski and Bird, 1965, Balhoff and Thompson, 2006, Duda et al, 1983, Eberhard et al, 2019) during the flow of polymeric fluid in the porous media. Effective viscosity and the exact analytical solution are useful in developing pore-network models for the flow of non-Newtonian fluids in porous media (Sochi and Blunt, 2008). The pore-network model for nonNewtonian fluid has wider engineering and industrial applications, e.g. it helps understand the complex interaction of the non-Newtonian fluids with tortuous and heterogeneous porous media at pore-scale.

A formulation to define an effective viscosity $\left(\eta_{\text {eff }}\right)$ of non-Newtonian fluids (having S-shape type rheology) for a given flow condition using measurable parameters is absent in the literature. Absence of an analytical solution to estimate 
the average velocity of Cross and Carreau fluid makes correlating Reynolds number with Darcy's friction factor arduous.

To address above discrepancy, we obtain an exact analytical solution for flow of a Meter model fluid through circular geometry. The analytical solution of the Meter model (MM) helps to define effective viscosity, Reynolds number and friction factor of non-Newtonian fluid flow using measurable parameters.

\section{Mathematical Formulation}

The Cauchy's momentum equation describes momentum transfer in any continuum. The state of stress at any point in the continuum (i.e. normal stresses, $\sigma_{n}$, and shear stresses, $\tau$ ) is defined using Cauchy's stress tensor $(\boldsymbol{\sigma})$. For an incompressible fluid, divergence of Cauchy's stress tensor is $\nabla \cdot \boldsymbol{\sigma}=-\nabla P+\nabla \cdot \tau$, where $\nabla P$ is the pressure gradient and $\tau$ is the deviatoric stress tensor. The constitutive equation of generalised Newtonian fluid (GNF) defines viscosity of the fluid as a non-linear function of second invariant of either rate-of-deformation tensor (i.e. $\boldsymbol{\tau}=2 \eta(\dot{\gamma}) \boldsymbol{D})($ Bird et al, 2007) or deviatoric stress tensor $(i . e . \boldsymbol{\tau}=2 \eta(\tau) \boldsymbol{D})$ (Meter and Bird, 1964; Steller and Iwko, 2018, Peters et al, 1999, Matsuhisa and Bird, 1965). Here, $\boldsymbol{D}=\frac{1}{2} \dot{\gamma}=\frac{1}{2}\left(\nabla \mathbf{u}+(\nabla \mathbf{u})^{T}\right)$, the magnitude of shear-rate is $|\dot{\gamma}|=\sqrt{\frac{\dot{\gamma}: \dot{\gamma}}{2}}($ Bird et al 2007$)$, the magnitude of shear stress is $|\tau|=\sqrt{\frac{\boldsymbol{\tau}: \boldsymbol{\tau}}{2}}$ (Meter and Bird 1964), and $\mathbf{u}$ is velocity vector. The constitutive equations for commonly used shear rate-dependent and shear stress-dependent GNF models are given in Table S1 of the Supporting Information (SI).

The intermolecular and inter-particles interactions in the fluid generate stresses (i.e. normal and shear stresses). These stresses govern the flow properties of the non-Newtonian fluids, including the viscosity of fluids. Thus, the stress-based model shall be adopted to describe the physics behind non-Newtonian fluid flow through void spaces. Meter (Meter and Bird, 1964) proposed his model in 1964 to describe S-shape type rheology of a non-Newtonian fluid. The Meter model is a modified version of the Ellis model (Bird and Carreau, 1968), Reiner-Philippoff model (Reiner, 1930; Philippoff, 1935) which were independently proposed in 1927, 1930, 1935 respectively; thus, it could also be renamed as the 'truncated EllisReiner-Philippoff model'.

The Meter model (Eq. 2) gives viscosity of a non-Newtonian fluid in terms of shear stress as follows (Meter and Bird, 1964)

$$
\eta=\eta_{\infty}+\frac{\eta_{0}-\eta_{\infty}}{1+\left(\frac{\tau}{\tau_{\mathrm{m}}}\right)^{\alpha-1}}
$$

here, $\eta[\mathrm{Pa} \cdot \mathrm{s}]$ is the shear viscosity at a given shear stress $(\tau) ; \eta_{0}[\mathrm{~Pa} \cdot \mathrm{s}]$ is the viscosity at the zero shear stress (i.e. zero shear viscosity); $\eta_{\infty}[\mathrm{Pa} \cdot \mathrm{s}]$ is the viscosity at the infinite shear stress (i.e. infinite shear viscosity); $\tau_{\mathrm{m}}[\mathrm{Pa}]$ is the critical shear stress of the non-Newtonian fluid at which viscosity of the solution drops to $\frac{\eta_{0}+\eta_{\infty}}{2} ; \alpha$ is the shear stress-dependent exponent of Meter model. $\eta_{0}, \eta_{\infty}$, and $\tau_{\mathrm{m}}$ are measurable quantities of the non-Newtonian fluid. Here we slightly modify the denotation of the Meter model by replacing $\alpha-1$ with $S$. Where, $S$ is 
the shear stress-dependent exponent of the Meter model (MM). The characteristic time $(\lambda)$ of the MM (Eq. 3) is a time at which fluid transition from Newtonian behaviour (zero shear viscosity) to shear thinning or shear thickening behaviour (i.e. at $\tau_{\mathrm{m}}$ ) occurs.

$$
\lambda=\frac{\eta_{0}+\eta_{\infty}}{2 \tau_{\mathrm{m}}}
$$

The shear rate of MM is

$$
\dot{\gamma}=\frac{\tau}{\eta_{\infty}+\frac{\eta_{0}-\eta_{\infty}}{1+\left(\frac{\tau}{\tau_{\mathrm{m}}}\right)^{S}}}
$$

We note that Eq. 4 applies to the Newtonian fluid (if $\eta_{0}=\eta_{\infty}, S=1, \tau_{\mathrm{m}}=1$ ), shear-thinning fluid (if $\eta_{0}>\eta_{\infty}, S>0, \tau_{\mathrm{m}}>0$ ), and shear-thickening fluid (if $\left.\eta_{0}<\eta_{\infty}, S>0, \tau_{\mathrm{m}}>0\right)$.

\subsection{Analytical solution}

Adopting Hagen-Poiseuille framework, the analytical solution is derived for a fully developed, incompressible, isothermal, laminar, steady, unidirectional flow of shear stress-dependent time-independent non-Newtonian fluid through a circular tube of radius $(R)$ under constant pressure gradient of $\left(\frac{d P}{d x}\right)$.

The shear rate $\dot{\gamma}(r)$ along radial direction $r$ is defined as,

$$
\dot{\gamma}(r)=\frac{\tau}{\eta},
$$

Substituting Eq. 2 in Eq. 5 , we obtain

$$
\dot{\gamma}(r)=\frac{\tau}{\eta_{\infty}+\frac{\eta_{0}-\eta_{\infty}}{1+\left(\frac{\tau}{\tau_{\mathrm{m}}}\right)^{S}}},
$$

The shear rate $\dot{\gamma}(r)$ in terms of velocity $u(r)$ along radial position $r$ is as defined in Eq. 7 ,

$$
\dot{\gamma}(r)=-\frac{d u(r)}{d r},
$$

The shear stress $(\tau)$ in a circular tube under a constant pressure gradient of $\frac{d P}{d x}$ in $x$-direction is as defined in Eq. 8 .

$$
\tau=-\frac{d P}{d x} \frac{r}{2}
$$

Now, substituting Eq. 7 and Eq. 8 in Eq. 6 we obtain,

$$
-\frac{d u(r)}{d r}=\frac{\left(-\frac{d P}{d x} \frac{r}{2}\right)}{\eta_{\infty}+\frac{\eta_{\infty}}{1+\left(-\frac{d P}{d x} \frac{r}{2 \tau_{\mathrm{m}}}\right)^{S}}},
$$


The velocity profile along the radial direction can be obtained as follows by integrating Eq. 9,

$$
\begin{aligned}
u(r)= & \frac{d P}{d x} \frac{r^{2}}{4 \eta_{0} \eta_{\infty}}\left(\eta_{0}+\left(\eta_{\infty}-\eta_{0}\right)_{2} \mathrm{~F}_{1}\left(1, \frac{2}{S} ; \frac{S+2}{S} ;-\frac{\eta_{\infty}}{\eta_{0}}\left(-\frac{d P}{d x} \frac{r}{2 \tau_{\mathrm{m}}}\right)^{S}\right)\right) \\
& + \text { Constant }
\end{aligned}
$$

here, ${ }_{2} F_{1}$ is the hypergeometric function as defined in the Eq. 17. At the wall of a circular tube, i.e., at $r=R$, by imposing the no-slip boundary condition, $u(R)=0$, Eq. 10 becomes,

$$
\text { Constant }=-\frac{d P}{d x} \frac{R^{2}}{4 \eta_{0} \eta_{\infty}}\left(\eta_{0}+\left(\eta_{\infty}-\eta_{0}\right){ }_{2} \mathrm{~F}_{1}\left(1, \frac{2}{S} ; \frac{S+2}{S} ;-\frac{\eta_{\infty}}{\eta_{0}}\left(-\frac{d P}{d x} \frac{R}{2 \tau_{\mathrm{m}}}\right)^{S}\right)\right)
$$

Substituting Eq. 11 in Eq. 10, we obtain velocity profile in a circular tube for the Meter model fluid as,

$$
\begin{aligned}
u(r)=-\frac{d P}{d x} \frac{1}{4 \eta_{0} \eta_{\infty}} & {\left[R^{2}\left(\eta_{0}+\left(\eta_{\infty}-\eta_{0}\right)_{2} \mathrm{~F}_{1}\left(1, \frac{2}{S} ; \frac{S+2}{S} ;-\frac{\eta_{\infty}}{\eta_{0}}\left(-\frac{d P}{d x} \frac{R}{2 \tau_{\mathrm{m}}}\right)^{S}\right)\right)\right.} \\
& \left.-r^{2}\left(\eta_{0}+\left(\eta_{\infty}-\eta_{0}\right)_{2} \mathrm{~F}_{1}\left(1, \frac{2}{S} ; \frac{S+2}{S} ;-\frac{\eta_{\infty}}{\eta_{0}}\left(-\frac{d P}{d x} \frac{r}{2 \tau_{\mathrm{m}}}\right)^{S}\right)\right)\right],
\end{aligned}
$$

The maximum velocity of the Meter model fluid in a circular tube will be at the center of the tube. On substituting $r=0$ in Eq 12, we obtain maximum velocity as follows

$$
U_{\max }=-\frac{d P}{d x} \frac{R^{2}}{4 \eta_{0} \eta_{\infty}}\left(\eta_{0}+\left(\eta_{\infty}-\eta_{0}\right)_{2} \mathrm{~F}_{1}\left(1, \frac{2}{S} ; \frac{S+2}{S} ;-\frac{\eta_{\infty}}{\eta_{0}}\left(-\frac{d P}{d x} \frac{R}{2 \tau_{\mathrm{m}}}\right)^{S}\right)\right)
$$

Considering $Q$ as the volumetric flow rate, the average velocity in a circular tube is given by

$$
U_{\mathrm{avg}}=\frac{Q}{\pi R^{2}}=\frac{1}{\pi R^{2}} \int_{0}^{R} 2 \pi r u(r) d r
$$

Substituting Eq. 12 in Eq. 14 , and integration and simplification we obtain average velocity during flow of a non-Newtonian Meter Model fluid as, 


$$
\begin{aligned}
U_{\text {avg }}=-\frac{d P}{d x} \frac{R^{2}}{8 \eta_{0} \eta_{\infty}} & \left(\eta_{\infty}-\eta_{0}\right)_{3} \mathrm{~F}_{2}\left(1, \frac{2}{S}, \frac{4}{S} ; \frac{S+2}{S}, \frac{S+4}{S} ;-\frac{\eta_{\infty}}{\eta_{0}}\left(-\frac{d P}{d x} \frac{R}{2 \tau_{\mathrm{m}}}\right)^{S}\right) \\
& \left.+2\left(\eta_{0}-\eta_{\infty}\right)_{2} \mathrm{~F}_{1}\left(1, \frac{2}{S} ; \frac{S+2}{S} ;-\frac{\eta_{\infty}}{\eta_{0}}\left(-\frac{d P}{d x} \frac{R}{2 \tau_{\mathrm{m}}}\right)^{S}\right)-\eta_{0}\right),
\end{aligned}
$$

The analytical solution to estimate the volumetric flow rate $(Q)$ of fluid in a circular tube/micro-capillary obeying the Meter model is given as

$$
\begin{aligned}
Q=-\frac{d P}{d x} \frac{\pi R^{4}}{8 \eta_{0} \eta_{\infty}} & \left(\left(\eta_{\infty}-\eta_{0}\right)_{3} \mathrm{~F}_{2}\left(1, \frac{2}{S}, \frac{4}{S} ; \frac{S+2}{S}, \frac{S+4}{S} ;-\frac{\eta_{\infty}}{\eta_{0}}\left(-\frac{d P}{d x} \frac{R}{2 \tau_{\mathrm{m}}}\right)^{S}\right)\right. \\
& \left.+2\left(\eta_{0}-\eta_{\infty}\right)_{2} \mathrm{~F}_{1}\left(1, \frac{2}{S} ; \frac{S+2}{S} ;-\frac{\eta_{\infty}}{\eta_{0}}\left(-\frac{d P}{d x} \frac{R}{2 \tau_{\mathrm{m}}}\right)^{S}\right)-\eta_{0}\right),
\end{aligned}
$$

here, the hypergeometric function ${ }_{2} F_{1}(a, b ; c ; z)$ is defined as in the Eq. 17 and the hypergeometric function ${ }_{3} F_{2}(a, b, c ; d, e ; z)$ is defined as in the Eq. 18

$$
\begin{gathered}
{ }_{2} F_{1}(a, b ; c ; z)=\sum_{n=1}^{\infty} \frac{(a)_{n}(b)_{n} z^{n}}{(c)_{n} n !}, \\
{ }_{3} F_{2}(a, b, c ; d, e ; z)=\sum_{n=1}^{\infty} \frac{(a)_{n}(b)_{n}(c)_{n} z^{n}}{(d)_{n}(e)_{n} n !}
\end{gathered}
$$

The hypergeom function of MATLAB was used to solve a generalised hypergeometric function of the analytical solution of the Meter model. The generalised hypergeometric function ${ }_{2} F_{1}(a, b ; c ; z)$ and ${ }_{3} F_{2}(a, b, c ; d, e ; z)$ are series as given in the Eq. S6 and S7 of SI respectively, which converge for $|z|<1$. Since, all parameters of hypergeometric function of the Meter model are constant values, the series of the generalised hypergeometric function of the Meter model can be solved using hypergeom function of MATLAB without error over a range of pressure gradient, radius and Meter model parameters.

Section S2 of the SI illustrates that the MM converts to existing shear stressdependent rheological models (i.e. Reiner-Philippoff model (Reiner, 1930, Philippoff, 1935), Ellis model (Matsuhisa and Bird, 1965)). The analytical solution for Newtonian fluid and Reiner-Philippoff model fluid can be derived using the analytical solution of the MM (see Section S2 of the SI).

Section S2.1 of the SI shows that Eq. 12 and Eq. 16 convert to Hagen-Poiseuille equation on substituting $\eta_{0}=\eta_{\infty}$. On equating Eq. 16 with Hagen-Poiseuille equation $\left(Q=\frac{\pi R^{4}}{8 \eta} \frac{d P}{d x}\right)$ and substituting $\frac{d P}{d x} \frac{R}{2}=\tau_{\mathrm{w}}$ in Eq. 16 we obtain an equation for an effective viscosity $\left(\eta_{\mathrm{eff}}\right)$ of fluid in terms of wall shear stress $\left(\tau_{\mathrm{w}}\right)$ as follows, 


$$
\begin{aligned}
\frac{1}{\eta_{\mathrm{eff}}}=\frac{1}{\eta_{0} \eta_{\infty}} & \left(\left(\eta_{\infty}-\eta_{0}\right)_{3} \mathrm{~F}_{2}\left(1, \frac{2}{S}, \frac{4}{S} ; \frac{S+2}{S}, \frac{S+4}{S} ;-\frac{\eta_{\infty}}{\eta_{0}}\left(\frac{\tau_{\mathrm{w}}}{\tau_{\mathrm{m}}}\right)^{S}\right)\right. \\
& \left.+2\left(\eta_{0}-\eta_{\infty}\right){ }_{2} \mathrm{~F}_{1}\left(1, \frac{2}{S} ; \frac{S+2}{S} ;-\frac{\eta_{\infty}}{\eta_{0}}\left(\frac{\tau_{\mathrm{w}}}{\tau_{\mathrm{m}}}\right)^{S}\right)-\eta_{0}\right),
\end{aligned}
$$

Eq. 19 helps determine the effective viscosity $\left(\eta_{\text {eff }}\right)$ of a non-Newtonian fluid from measurable parameters $\eta_{0}, \eta_{\infty}, \tau_{\mathrm{m}}, S, \tau_{\mathrm{w}}, R$ and $\frac{d P}{d x}$. On comparing Eq. 16 with Darcy's law $\left(Q_{\text {darcy }}=\frac{k A}{\eta} \frac{d P}{d x}\right)$, we obtain an effective viscosity value as given in Eq. 19 and permeability $(k)$ of the porous media as $\left(k=\frac{r_{\text {eff }}^{2}}{8}\right)$. Here $r_{\text {eff }}$ is the hydraulic radius of porous medium. Thus, the effective viscosity determined using Eq. 19 could be advantageous in determining Darcy scale flow rate and velocity of a non-Newtonian fluid in a porous medium.

We observed that the effective viscosity value obtained using Eq. 19 consistently appears at a distance of $(0.8 R)$ from the centre of a capillary for all experimental flow data utilised in present work. This suggests that the value of effective viscosity is equal to the viscosity value at a distance of $\beta R$ from the centre of the tube, where $0<\beta<1$. Thus, the approximate effective viscosity of the MM fluid for a given flow condition will be as in Eq. 20

$$
\eta_{\mathrm{eff}}=\eta_{\infty}+\frac{\eta_{0}-\eta_{\infty}}{1+\left(\frac{\beta R}{2 \tau_{\mathrm{m}}} \frac{d P}{d x}\right)^{S}}
$$

Here, $\beta=0.8$ for flow through a circular geometry. We note that different geometric shape will have different $\beta$ value. Eq. 20 is an easy-to-use equation for estimation of the effective viscosity of the fluid for a given fluid flow condition compared to Eq. 19. The advanced mathematical tool is required to estimate effective viscosity value using Eq. 19 due to presence of hypergeometric function in the equation. We obtain a semi-analytical solution for the flow rate of MM fluid by substituting Eq. 20 in Hagen-Poiseuille equation as,

$$
Q=\frac{d P}{d x} \frac{\pi R^{4}}{8\left(\eta_{\infty}+\frac{\eta_{0}-\eta_{\infty}}{1+\left(\frac{\beta R}{2 \tau_{\mathrm{m}}} \frac{d P}{d x}\right)^{S}}\right)}
$$

We define the effective Reynolds number $\left(R e_{\text {eff }}\right)$ of MM fluid as

$$
R e_{\mathrm{eff}}=\frac{2 \rho U_{\mathrm{avg}} R}{\eta_{\mathrm{eff}}}
$$

The Darcy's friction factor $\left(f_{D}\right)$ during any type of a fluid flow is $f_{D}=$ $\frac{d P}{d x} \frac{4 R}{\rho U_{\text {avg }}^{2}}$. We obtain effective friction factor $\left(f_{\text {eff }}\right)$ for laminar flow of MM fluid 
Table 1 MM parameters of Campagnolo et al (2013); Escudier et al 2005); Brown and Jaeger (2012)

\begin{tabular}{|c|c|c|c|c|c|c|}
\hline \multirow[t]{3}{*}{ Parameter } & \multirow{2}{*}{\multicolumn{4}{|c|}{$\begin{array}{l}\text { Shear thinning fluid } \\
\text { Xanthan gum (XG) concentration }(\mathrm{g} / \mathrm{L}) \\
\text { (Campagnolo et al } \mid 2013)\end{array}$}} & PAA & $\begin{array}{l}\text { Shear thickening fluid } \\
\text { Cornstarch (CS) }\end{array}$ \\
\hline & & & & & (Escudier et al 2005) & (Brown and Jaeger 2012) \\
\hline & $3 \mathrm{~g} / \mathrm{L}$ & $1 \mathrm{~g} / \mathrm{L}$ & $0.25 \mathrm{~g} / \mathrm{L}$ & 0 & $0.125 \%$ & $\phi=0.45$ \\
\hline$\eta_{0}[\mathrm{~Pa} . \mathrm{s}]$ & 1.2 & 0.08 & 0.01 & 0.000896 & 0.2257 & 1.8 \\
\hline$\eta_{\infty}[$ Pa.s $]$ & 0.000896 & 0.000896 & 0.000896 & 0.000896 & 0.000896 & 46 \\
\hline$\tau_{\mathrm{m}}[\mathrm{Pa}]$ & 1.1 & 0.105 & 0.028 & 1 & 0.24 & 100 \\
\hline$S$ & 1.87 & 1.11 & 0.75 & 1 & 1.124 & 1.1 \\
\hline$\lambda[s]$ & 0.546 & 0.385 & 0.195 & & 0.47 & 0.24 \\
\hline
\end{tabular}

(Eq. 23) by substituting the MM analytical solution for average velocity (Eq. 15 in Darcy's friction factor equation.

$$
f_{\mathrm{eff}}=\frac{256}{\rho R^{3}\left(\frac{d P}{d x}\right)} \eta_{\mathrm{eff}}^{2}=\frac{128}{\rho R^{2} \tau_{\mathrm{w}}} \eta_{\mathrm{eff}}^{2}
$$

\section{Results and Discussion}

3.1 Meter model for shear thinning and shear thickening fluids

Fig 1 shows a statistically good fit of experimental and MM predicted (Eq. 2) viscosity-shear stress and shear rate-shear stress data of a shear-thinning fluid (xanthan gum fluid of (Campagnolo et al, 2013) over range of concentration, polyacrylamide (PAA) fluid of (Escudier et al, 2005)) and shear-thickening fluid (cornstarch fluid in glycerol-water mixture of (Brown and Jaeger, 2012)). The model parameters are estimated using Excel-Solver methods that use GRG nonlinear algorithm (Kemmer and Keller, 2010). Fig. 1 shows that cornstarch fluid has a shear-thinning region at lower shear stresses and high shear stresses. Literature reports similar behaviour for most of shear thickening fluids; thus an application of MM for shear thickening fluids should be restricted to the shear thickening region of the viscosity-shear stress curve.

The material parameters of MM (Table 1 implies that the zero shear viscosity $\left(\eta_{0}\right)$ and critical shear stress $\left(\tau_{\mathrm{m}}\right)$ increases exponentially and the shear-thinning property of xanthan gum fluid (i.e. exponent $S$ ) increases linearly with an increase in the concentration of the xanthan gum fluid. This implies that MM helps to quantitatively correlate effect of physico-chemical parameters (e.g. XG concentration in present case) on rheology of a of shear thinning and shear thickening fluids using measurable parameters.

\subsection{The factor $\beta$}

To determine $\beta$ over a range of pressure gradient, radius and Meter model parameter, we substitute Eq. 20 in Eq. 19 and solved resultant equation for $\beta$. Fig 2 shows that the factor $\beta$ values ranged from 0.73 to 0.82 over a range a pressure-gradient, radius and Meter model parameters. The average value of the $\beta=0.8$ suggests that an effective viscosity of the fluid measured at a distance $0.8 R$ distance from 

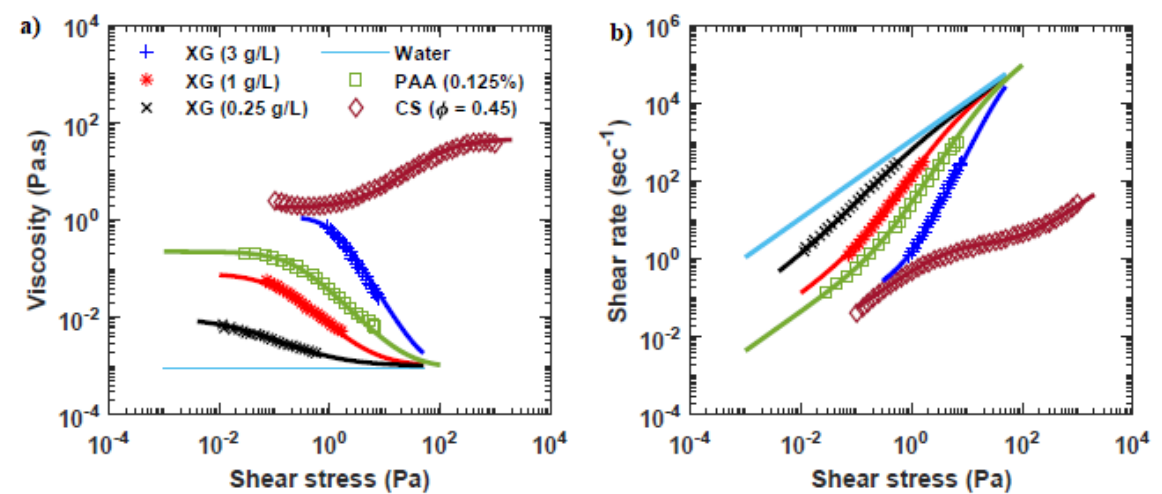

Fig. 1 (a) Shear viscosity as a function of shear stress (Eq. 2), (b) shear rate as a function of shear stress (Eq. 4) modelled using MM. An experimental rheological data of xanthan gum (XG) fluid over range of concentration $(3 \mathrm{~g} / \mathrm{L}, 1 \mathrm{~g} / \mathrm{L}, 0.25 \mathrm{~g} / \mathrm{L}$, water) Campagnolo et al 2013); 0.125\% polyacrylamide (PAA) fluid (Escudier et al, 2005), cornstarch (CS) fluid having volume fraction of 0.45 (Brown and Jaeger 2012) modelled using MM. Continuous line shows MM predications. The material parameters of $\mathrm{MM}$ are given Table 1 The root means square error (RMSE) range from $3.4 \times 10^{-3}$ to $1.6 \times 10^{-1}$.

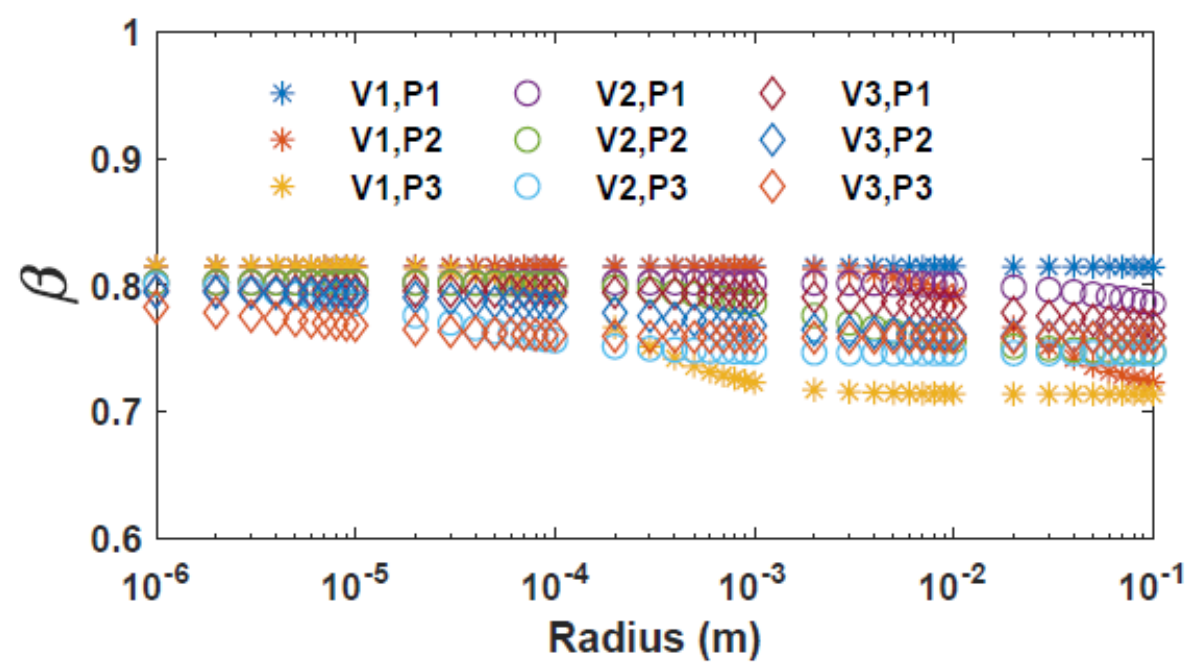

Fig. 2 The factor $\beta$ over a range of a pressure gradient, radius and Meter model parameters. $\mathrm{V} 1, \mathrm{~V} 2$, and $\mathrm{V} 3$ represents viscosity of the $3 \mathrm{~g} / \mathrm{L}, 1 \mathrm{~g} / \mathrm{L}$ and $0.25 \mathrm{~g} / \mathrm{L}$ xanthan gum fluid, respectively, as given in the Table $1 \mathrm{P} 1=10^{2} \mathrm{~Pa} / \mathrm{m}, \mathrm{P} 2=10^{4} \mathrm{~Pa} / \mathrm{m}$ and $\mathrm{P} 3=10^{6} \mathrm{~Pa} / \mathrm{m}$.

the centre of the capillary can be considered as an approximate effective viscosity of the fluid. 

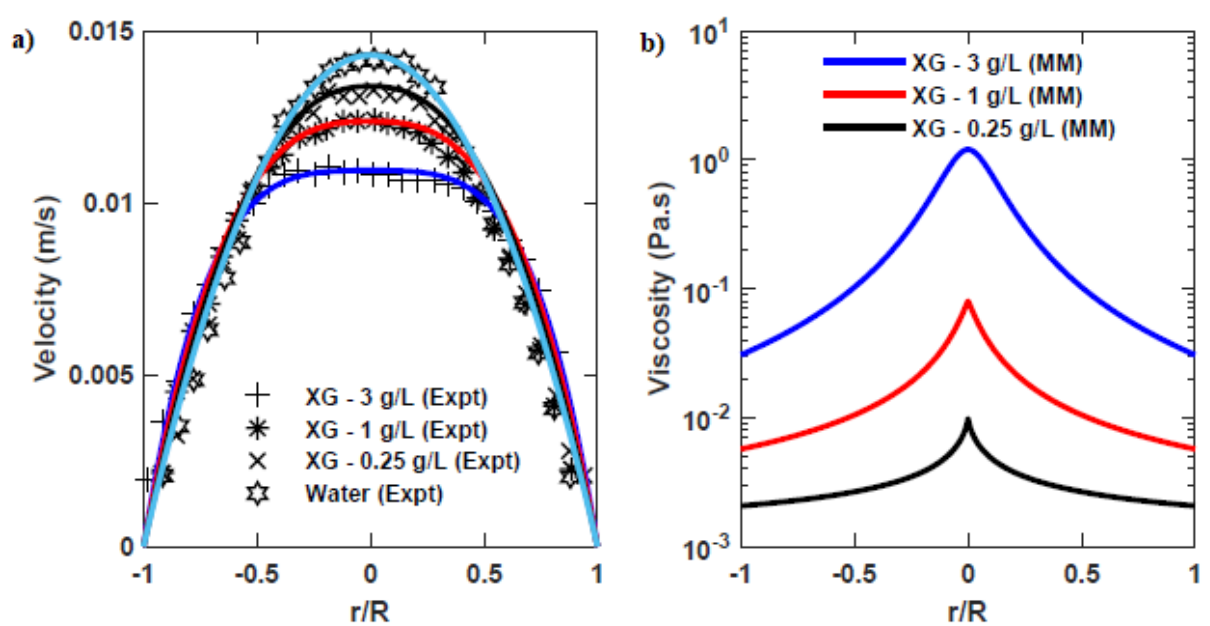

Fig. 3 Comparison of experimental (Campagnolo et al, 2013) and MM analytical solution predicated by Eq. 12 (a) radial velocity profile, and (b) radial viscosity profile during flow of a xanthan gum $(\mathrm{XG}$ ) through a circular micro-capillary (radius $160 \mu \mathrm{m}$ ) over a range of $\mathrm{XG}$ concentrations. The material parameters of MM are given Table 1 The root means square error (RMSE) range from $3.4 \times 10^{-4}$ to $6.3 \times 10^{-2}$.

\subsection{Validation of the analytical solution of the Meter model}

a) Flow-through a micro-capillary

An experimental velocity profile of (Campagnolo et al, 2013) gave good fit with the analytical solution of the MM for radial velocity profile (Eq. 12) at the pressure gradients of $92,000 \mathrm{~Pa} / \mathrm{m}, 16,500 \mathrm{~Pa} / \mathrm{m}, 4,900 \mathrm{~Pa} / \mathrm{m}$ and $2,000 \mathrm{~Pa} / \mathrm{m}$ during flow of $3 \mathrm{~g} / \mathrm{L}, 1 \mathrm{~g} / \mathrm{L}, 0.25 \mathrm{~g} / \mathrm{L}$ xanthan gum fluid and water $(0.4 \%$ milk), respectively (see Fig. 3a). Moreover, the analytical (Eq. 16) and semi-analytical (Eq. 21) solution of the MM for flow rate could correctly determine the experimental flow rate of $30 \mu \mathrm{L} / \mathrm{min}$ through a circular microfluidic channel of radius $160 \mu \mathrm{m}$. Fig. 3p suggests that the viscosity profile of the non-Newtonian shear-thinning fluid is bell-shaped in a circular geometry. The viscosity increases gradually near the wall and drastically in the central region of the micro-capillary. The effective viscosity estimated using Eq. 19 and Eq. 20, for flow of a $3 \mathrm{~g} / \mathrm{L}, 1 \mathrm{~g} / \mathrm{L}$ and $0.25 \mathrm{~g} / \mathrm{L}$ xanthan gum fluid through a micro-capillary is 0.041 Pa.s, 0.0075 Pa.s and 0.0022 Pa.s, respectively. We note that the analytical solution of the Meter model fluids is applicable for shear thickening fluid and needs validation using experimental data.

b) Flow-through a tube

Escudier et al. (Escudier et al, 2005) measured radial velocity profile of $0.125 \%$ polyacrylamide (PAA) fluid flow in a circular tube (radius $5 \mathrm{~cm}$ ) over a range of Reynolds number $\left(R e_{\text {expt }}\right)$, wherein the authors defined Reynolds number $\left(R e_{\text {expt }}\right)$ using shear viscosity at the wall of pipe. Fig 4 a depicts that the analytical solution of the MM for the velocity profile (Eq. 12) could correctly predict the experimentally observed radial velocity profile at $R e_{\text {expt }}=676$ and $R e_{\text {expt }}=1620$. The analytical solution of MM is restricted to laminar flow and Fig 4 a suggests that 

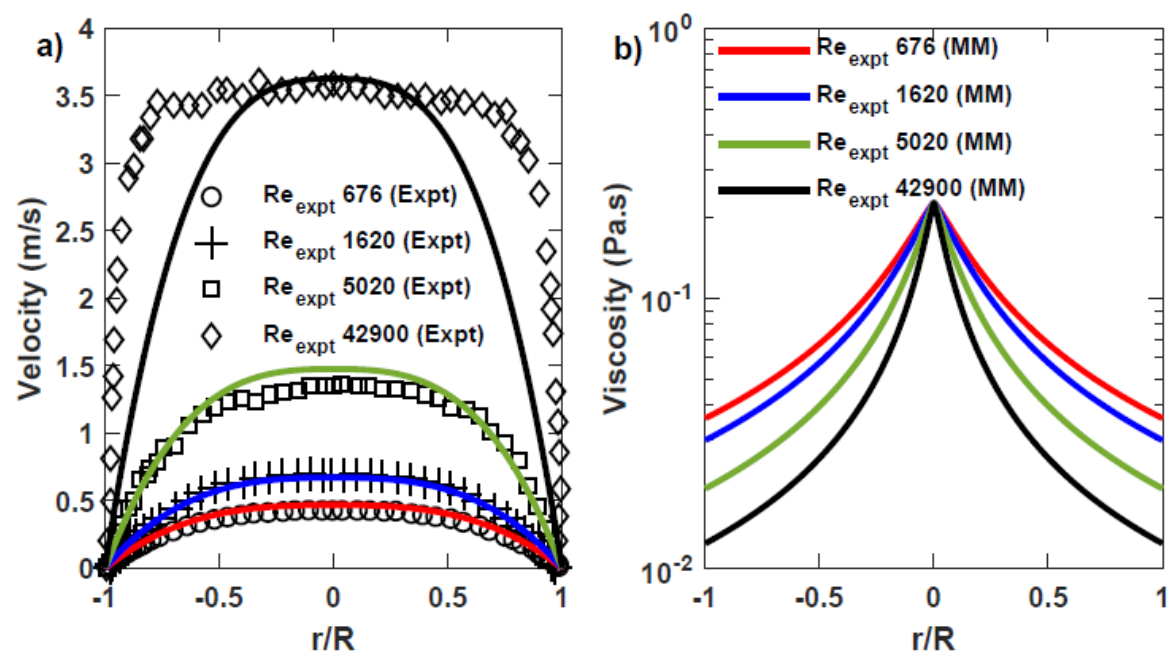

Fig. 4 Comparison of experimental (Escudier et al 2005) and MM analytical solution predicated by Eq. 12 (a) radial velocity profile, and (b) radial viscosity profile during flow of a $0.125 \%$ polyacrylamide (PAA) fluid through a circular micro-capillary (radius $0.05 \mathrm{~m}$ ) over a range of Reynolds numbers. The material parameters of MM are given Table 1 The root means square error (RMSE) range from $3.4 \times 10^{-4}$ to $8.5 \times 10^{-3}$ for $R e_{\text {expt }}<1620$.

Table 2 Validation of the analytical solution of MM for flow through a circular tube

\begin{tabular}{|c|c|c|c|c|c|c|c|c|c|}
\hline \multicolumn{3}{|c|}{ Experimental observation } & scudier & al 2005 & \multicolumn{5}{|c|}{ MM Estimate } \\
\hline$R e_{\text {expt }}$ & $\begin{array}{c}\frac{d P}{d x} \\
(\mathrm{~Pa} / \mathrm{m})\end{array}$ & $\begin{array}{l}U_{\text {expt }} \\
(\mathrm{m} / \mathrm{s})\end{array}$ & $\begin{array}{c}\eta_{\mathrm{w}} \\
(\text { Pa.s })\end{array}$ & $f_{\mathrm{D}}$ & $\begin{array}{c}\eta_{\mathrm{eff}} \\
(\mathrm{Pa} . \mathrm{s})\end{array}$ & $\begin{array}{c}Q \\
\left(\mathrm{~m}^{3} / \mathrm{s}\right)\end{array}$ & $\begin{array}{c}U_{\mathrm{Avg}} \\
(\mathrm{m} / \mathrm{s})\end{array}$ & $R e_{\mathrm{eff}}$ & $f_{\text {eff }}$ \\
\hline 676 & 38.5 & 0.256 & 0.0376 & 0.1135 & 0.0467 & 0.002 & 0.2578 & 552 & 0.1158 \\
\hline 1620 & 51 & 0.447 & 0.0276 & 0.0510 & 0.0358 & 0.0035 & 0.448 & 1241 & 0.0516 \\
\hline 5020 & 70 & 0.939 & 0.0187 & 0.0159 & 0.0262 & 0.0065 & 0.8339 & 3178 & 0.0201 \\
\hline 42900 & 109 & 3.36 & 0.0078 & 0.0019 & 0.0156 & 0.0172 & 2.184 & 14007 & 0.0046 \\
\hline
\end{tabular}

at $R e_{\text {expt }}=5020$ PAA flow is in transition phase and at $R e_{\text {expt }}=42900$ is in turbulent phase. Fig $4 \mathrm{~b}$ shows that the shape of the viscosity profile becomes more acute at the centre of the circular tube with an increase in Reynolds number or pressure gradient.

The effective Reynolds number $\left(R e_{\text {eff }}\right)$ values calculated using Eq. 22 are drastically different from $R e_{\text {expt }}$ estimated by (Escudier et al, 2005) (see Table 2). The analytical solution of the MM could correctly estimate the velocity profile, flow rate, average velocity and friction factor within the error range $( \pm 5 \%)$, when $R e_{\text {eff }}$ of PAA is less than 1241 (at $\frac{d P}{d x}<51 \mathrm{~Pa} / \mathrm{m}$ ). On the contrary, when $R e_{\text {eff }}$ was 3178 (at $\frac{d P}{d x}=70 \mathrm{~Pa} / \mathrm{m}$ ) and 14007 (at $\frac{d P}{d x}=109 \mathrm{~Pa} / \mathrm{m}$ ), flow becomes turbulent, and velocity profile could not be matched with the experimental data. This result suggests that the Reynolds number determined using the Eq. 22 gives comparable results with the Reynolds number of a Newtonian fluid in a circular tube. Thus, it is convenient to define a non-Newtonian fluid flow as (i) laminar if $R e_{\text {eff }}<2300$, (ii) turbulent if $R e_{\text {eff }}>2900$, and (iii) transition zone if $2300<R e_{\text {eff }}<2900$.

As given in Table 2, the friction factor of the MM determined using Eq. 23 and the experimental friction factor $\left(f_{\mathrm{D}}\right)$ determined using Darcy's law give approxi- 
mately same result for a laminar flow $\left(R e_{\text {eff }}<1241\right)$. As expected for the turbulent flow, the friction factor estimate has a difference of $26 \%$ at $\frac{d P}{d x}=70 \mathrm{~Pa} / \mathrm{m}$ and $142 \%$ at $\frac{d P}{d x}=109 \mathrm{~Pa} / \mathrm{m}$. For a Newtonian fluid, the relationship between the Reynolds number and the friction factor for laminar flow through a circular tube is given as $R e=\frac{64}{f_{\mathrm{D}}}$. The same relationship applies to non-Newtonian fluid described by the MM. The $R e_{\text {eff }}$ estimated using Eq. 22 is equivalent to the Reynolds number estimated using $R e_{\mathrm{eff}}=\frac{64}{f_{\mathrm{D}}}$, if an experimental error of up to $5 \%$ is taken into account for laminar flow of (Escudier et al, 2005).

\subsection{The effective friction factor}

A simple algebraic formula for the effective friction factor as a function of pressure gradient, radius and Meter model parameters $\left(\eta_{\infty}, \eta_{0}, \tau_{\mathrm{m}}, S\right)$, as presented in Eq. 24. can be obtained on substituting Eq. 20 in Eq. 23. This is a semi-analytical formula for the effective friction factor of the Meter model fluid.

$$
f_{\mathrm{eff}}=\frac{256}{\rho R^{3}\left(\frac{d P}{d x}\right)}\left(\eta_{\infty}+\frac{\eta_{0}-\eta_{\infty}}{1+\left(\frac{0.8 R}{2 \tau_{\mathrm{m}}} \frac{d P}{d x}\right)^{S}}\right)^{2}
$$

Fig 5 shows that the effective friction factor estimated using Eq. 23 closely matches with the $f_{\text {eff }}$ estimated using Eq. 24 over a range of xanthan gum concentrations. Fig 5 also shows a non-linear relationship between the pressure gradient and the effective friction factor. An increase in the radius of the circular capillary/pipe decreases the friction factor. Moreover, increase in the polymeric concentration of xanthan gum fluid shows increase in $f_{\text {eff }}$ over a range of pressure gradients and radii. The results suggest that the Eq. 24 can be utilised to determine $f_{\text {eff }}$ of a non-Newtonian fluid using measurable parameters (i.e. radius, pressure gradient, and Meter model parameters).

\subsection{Radial viscosity variation}

We determined radial viscosity variation (\%) during flow of an MM fluid through a circular tube/micro-capillary using Eq. 25.

$$
\text { Radial viscosity variation }(\%)=\frac{\left(\eta_{\text {center }}-\eta_{\mathrm{w}}\right)}{\eta_{\text {center }}} \times 100
$$

here, $\eta_{\text {center }}$ and $\eta_{\mathrm{w}}$ is the viscosity at the centre and wall of a circular tube, respectively. The variation of viscosity along the radial direction in a circular tube/capillary depends on radius and pressure gradient, i.e., on shear stress. Fig. 6a shows estimated radial viscosity variation (\%) at a various pressure gradients $\left(1 \mathrm{~Pa} / \mathrm{m}\right.$ to $\left.10^{8} \mathrm{~Pa} / \mathrm{m}\right)$ and a radius $(0.05 \mu \mathrm{m}-500 \mathrm{~mm})$ during XG-3 g/L fluid flow of (Campagnolo et al, 2013) in a circular tube/capillary. Similarly, Fig. 6p elucidates radial viscosity variation $(\%)$ at various Reynolds number $\left(10^{-9}\right.$ to $\left.10^{\prime}\right)$ and pressure gradient $\left(10^{-1}-10^{6} \mathrm{~Pa} / \mathrm{m}\right)$. 

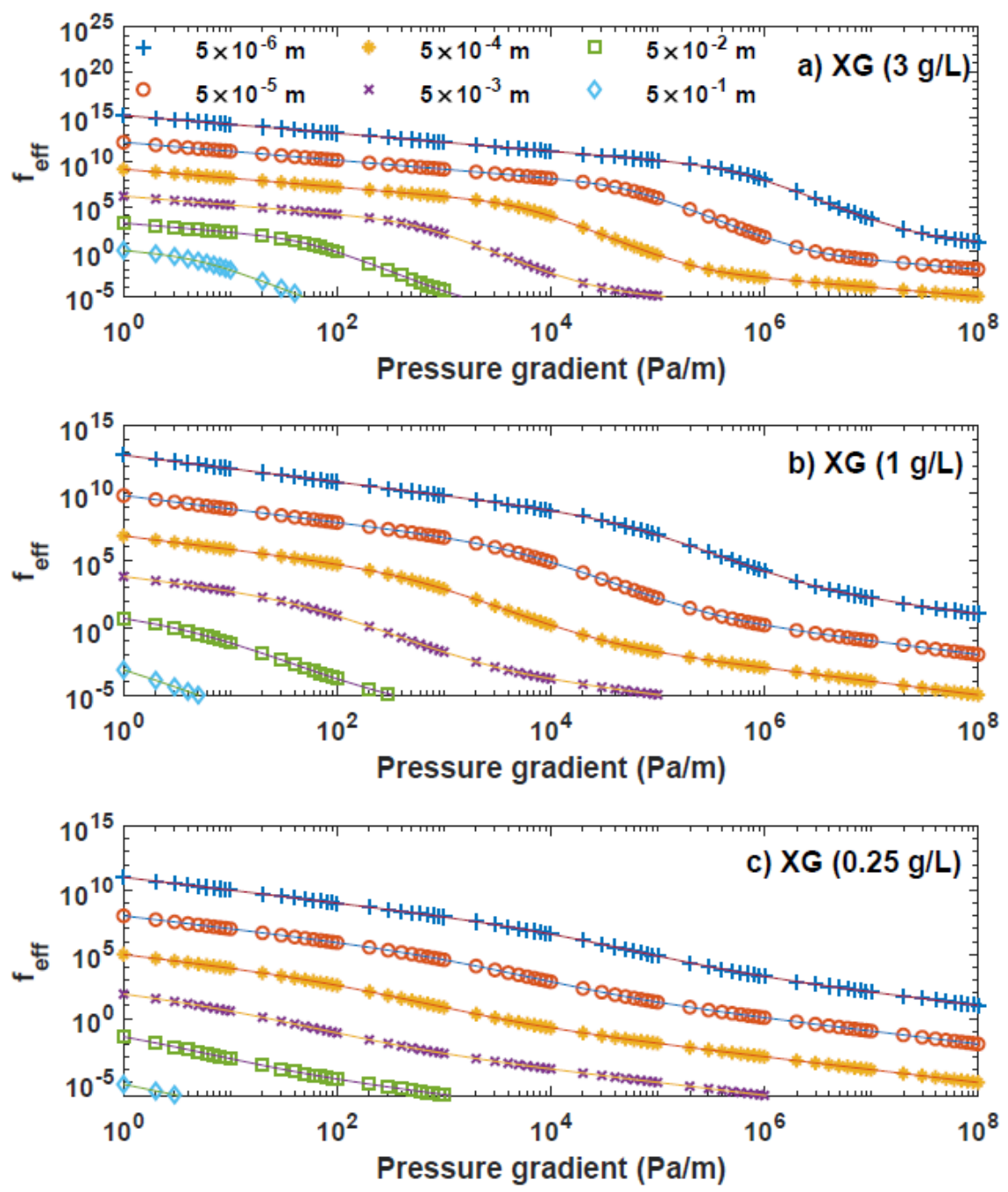

Fig. 5 The effective friction factor as a function of pressure gradient over a range of radii ( 5 $\mu \mathrm{m}$ to $0.5 \mathrm{~m}$ ) and xanthan gum (XG) concentrations. (a) XG: $3 \mathrm{~g} / \mathrm{L}$, (b) XG: $1 \mathrm{~g} / \mathrm{L}$, and (c) XG: $0.25 \mathrm{~g} / \mathrm{L}$. Symbols show $f_{\text {eff }}$ estimated using Eq. 23 and continuous solid lines show $f_{\text {eff }}$ estimated using Eq. 24 for radius $(R)$ of capillary/tube. Meter model parameters are given in Table 1

It appears from Fig. 6a that for each radius, there exists a critical pressure gradient value below which the viscosity variation is insignificant. If radial viscosity variation of $10^{-1} \%$ is considered as an insignificant variation, then $10^{6} \mathrm{~Pa} / \mathrm{m}, 10^{5}$ $\mathrm{Pa} / \mathrm{m}, 10^{4} \mathrm{~Pa} / \mathrm{m}, 10^{3} \mathrm{~Pa} / \mathrm{m}, 10^{2} \mathrm{~Pa} / \mathrm{m}, 10^{1} \mathrm{~Pa} / \mathrm{m}$ will be the critical/threshold pressure gradient values for capillaries of radius $0.05 \mu \mathrm{m}, 0.5 \mu \mathrm{m}, 5 \mu \mathrm{m}, 50 \mu \mathrm{m}, 500$ $\mu \mathrm{m}$, and $5 \mathrm{~mm}$, respectively. Below these thresholds the viscosity variation could be considered as insignificant or effectively constant. The choice of viscosity variation 

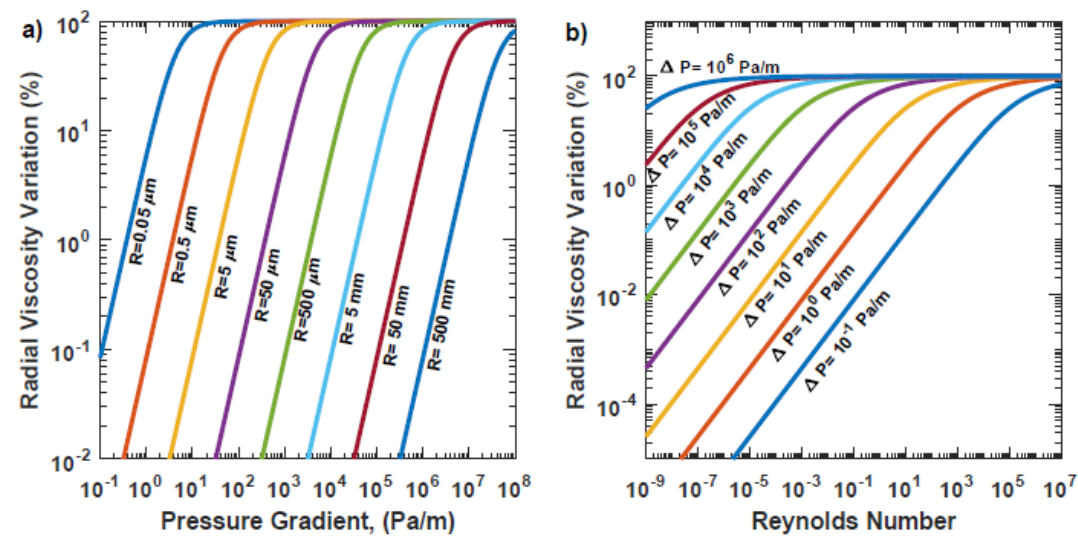

Fig. 6 (a) Effect of pressure gradient and radius $(R)$ on the radial viscosity variation (\%) during flow of a xanthan gum (XG, $3 \mathrm{~g} / \mathrm{L}$ ) fluid of (Campagnolo et al 2013) in a circular capillary/tube, (b) effect of Reynolds number and pressure gradient on the radial viscosity variation (\%) during flow of a xanthan gum (XG, $3 \mathrm{~g} / \mathrm{L}$ ) fluid of (Campagnolo et al 2013) in a circular capillary/tube.

as "an insignificant" might depend on the viscosity at a zero shear stress $\left(\eta_{0}\right)$, and effect of the viscosity variation on the output of work. Fig. 6a also suggests that with an increase in the radius of a capillary, magnitude of the critical pressure gradient decreases.

Similarly, Fig. 6p shows that, for each pressure gradient, there exists a critical Reynolds number below which the viscosity variation is insignificant. Fig. 6p shows that if pressure gradient of the XG-3 g/L fluid through a circular tube/microcapillary is lower than $100 \mathrm{~Pa} / \mathrm{m}$ and Reynolds number is below 0.001 , the radial viscosity variation is insignificant. Overall, Fig. 6illustrates that if applied pressure gradient or Reynolds number are below their threshold/critical values, the nonNewtonian fluid flow can be modelled as a Newtonian fluid with zero shear stress viscosity as its constant viscosity. This means that the fluid flow through capillary can be modelled using the Hagen-Poiseuille equation.

\section{Conclusions}

The Meter model was validated against experimental rheological data of cornstarch fluid, polyacrylamide fluid, and xanthan gum fluid. The analytical solution of the MM was validated against the experimentally measured velocity profile during flow of non-Newtonian fluids (xanthan gum and polyacrylamide) through a circular micro-capillary of radius $160 \mu \mathrm{m}$ and a circular tube of radius $0.05 \mathrm{~m}$. An easy to use semi-analytical solution (similar to Hagen-Posseuille equation) is formulated for computation of an effective viscosity and a flow rate. The effective Reynolds number estimated using formulation presented in this work helps to correctly characterise fluid flow in laminar, turbulent and transition flow. The Darcy's friction factor computed using formulation given in the current work, and experimental friction factor gave equivalent results for laminar flow. Finally, this work suggested that there exists a threshold pressure gradient for a given radius 
and a critical effective Reynolds number below which the radial viscosity variation is insignificant, and it will be convenient to assume a constant viscosity for such flows.

The method proposed in the present work to compute effective viscosity, average velocity, radial velocity profile, flow rate, effective Reynolds number and effective friction factor using measurable flow parameters will help to understand the behaviour of non-Newtonian fluids comprehensively. In future, we will apply the proposed model for the flow of non-Newtonian fluids in heterogeneous porous media using OpenFOAM and pore-Network model and compare our results to similar recent publications, for example, (Zami-Pierre et al, 2018).

\section{Supporting Information}

The SI includes:

- Time-independent non-Newtonian fluid empirical models (Table S1);

- Analytical solution for existing rheological models (Section S2);

- The generalised hypergeometric function (Section S3)

\section{Acknowledgement}

T.S. gratefully appreciates Rajashri Shahu Maharaj Foreign Scholarship, Government of Maharashtra, India that has enabled him to undertake $\mathrm{PhD}$ research at the University of Manchester.

\section{Conflict of interests}

The authors declare that they have no conflict of interest.

\section{References}

Balhoff MT, Thompson KE (2006) A macroscopic model for shear-thinning flow in packed beds based on network modeling. Chemical Engineering Science 61(2):698-719

Bird RB, Carreau PJ (1968) A nonlinear viscoelastic model for polymer solutions and melts-I. Chemical Engineering Science 23(5):427-434

Bird RB, Armstrong R, Hassager O (1987) Fluid mechanics, dynamics of polymeric liquids, Vol. 1

Bird RB, Stewart WE, Lightfoot EN (2007) Transport Phenomena. John Wiley \& Sons

Brown E, Jaeger HM (2012) The role of dilation and confining stresses in shear thickening of dense suspensions. Journal of Rheology 56(4):875-923

Campagnolo L, Nikolić M, Perchoux J, Lim YL, Bertling K, Loubiere K, Prat L, Rakić AD, Bosch T (2013) Flow profile measurement in microchannel using the optical feedback interferometry sensing technique. Microfluidics and Nanofluidics 14(1-2):113-119 
Cross MM (1965) Rheology of non-Newtonian fluids: a new flow equation for pseudoplastic systems. Journal of Colloid Science 20(5):417-437

Duda JL, Hong SA, Klaus EE (1983) Flow of polymer solutions in porous media: inadequacy of the capillary model. Industrial \& Engineering Chemistry Fundamentals 22(3):299-305

Eberhard U, Seybold HJ, Floriancic M, Bertsch P, Jiménez-Martínez J, Andrade Jr JS, Holzner M (2019) Determination of the effective viscosity of non-newtonian fluids flowing through porous media. Frontiers in Physics 7:71

Escudier M, Poole R, Presti F, Dales C, Nouar C, Desaubry C, Graham L, Pullum L (2005) Observations of asymmetrical flow behaviour in transitional pipe flow of yield-stress and other shear-thinning liquids. Journal of Non-Newtonian Fluid Mechanics 127(2-3):143-155

Ferrás L, Afonso A, Alves M, Nóbrega J, Pinho F (2020) Newtonian and viscoelastic fluid flows through an abrupt 1: 4 expansion with slip boundary conditions. Physics of Fluids 32(4):043,103

Kemmer G, Keller S (2010) Nonlinear least-squares data fitting in excel spreadsheets. Nature protocols 5(2):267

Kim SK (2018) Flow-rate based method for velocity of fully developed laminar flow in tubes. Journal of Rheology 62(6):1397-1407

Matsuhisa S, Bird RB (1965) Analytical and numerical solutions for laminar flow of the non-Newtonian Ellis fluid. AIChE Journal 11(4):588-595

Meter DM (1964) Tube flow of non-newtonian polymer solutions: Part II. turbulent flow. AIChE Journal 10(6):881-884

Meter DM, Bird RB (1964) Tube flow of non-newtonian polymer solutions: Part I. laminar flow and rheological models. AIChE Journal 10(6):878-881

Metzner A, Reed J (1955) Flow of non-newtonian fluids - correlation of the laminar, transition, and turbulent-flow regions. AlChe Journal 1(4):434-440

Peralta JM, Meza BE, Zorrilla SE (2014) Mathematical modeling of a dip-coating process using a generalized Newtonian fluid. 1. Model development. Industrial \& Engineering Chemistry Research 53(15):6521-6532

Peralta JM, Meza BE, Zorrilla SE (2017) Analytical solutions for the free-draining flow of a Carreau-Yasuda fluid on a vertical plate. Chemical Engineering Science 168:391-402

Peters GW, Schoonen JF, Baaijens FP, Meijer HE (1999) On the performance of enhanced constitutive models for polymer melts in a cross-slot flow. Journal of Non-Newtonian Fluid Mechanics 82(2-3):387-427

Philippoff W (1935) Zur Theorie der Strukturviskositaet. I. Kolloid-Zeitschrift 71(1):1-16

Reiner M (1930) In search for a general law of the flow of matter. Journal of Rheology (1929-1932) 1(3):250-260

Sadowski TJ, Bird RB (1965) Non-newtonian flow through porous media. i. theoretical. Transactions of the Society of Rheology 9(2):243-250

Savins J (1969) Non-newtonian flow through porous media. Industrial \& Engineering Chemistry 61(10):18-47

Sochi T (2015) Analytical solutions for the flow of Carreau and Cross fluids in circular pipes and thin slits. Rheologica Acta 54(8):745-756

Sochi T, Blunt MJ (2008) Pore-scale network modeling of ellis and herschel-bulkley fluids. Journal of Petroleum Science and Engineering 60(2):105-124 
Steller R, Iwko J (2018) New generalized newtonian fluid models for quantitative description of complex viscous behavior in shear flows. Polymer Engineering \& Science 58(8):1446-1455

Tsakiroglou C, Theodoropoulou M, Karoutsos V (2003a) Fluid flow in fractured formations. In: New Paradigms in Subsurface Prediction, Springer, pp 161-172

Tsakiroglou C, Theodoropoulou M, Karoutsos V, Papanicolaou D, Sygouni V (2003b) Experimental study of the immiscible displacement of shear-thinning fluids in pore networks. Journal of Colloid and Interface Science 267(1):217-232

Tsakiroglou CD (2002) A methodology for the derivation of non-darcian models for the flow of generalized newtonian fluids in porous media. Journal of NonNewtonian Fluid Mechanics 105(2-3):79-110

Yasuda K (1979) Investigation of the analogies between viscometric and linear viscoelastic properties of polystyrene fluids. PhD thesis, Massachusetts Institute of Technology

Yilmaz F, Gundogdu MY (2008) A critical review on blood flow in large arteries; relevance to blood rheology, viscosity models, and physiologic conditions. KoreaAustralia Rheology Journal 20(4):197-211

Zami-Pierre F, de Loubens R, Quintard M, Davit Y (2018) Effect of disorder in the pore-scale structure on the flow of shear-thinning fluids through porous media. Journal of Non-Newtonian Fluid Mechanics 261:99-110 